\title{
Improved predictive current model control based on adaptive PR controller for standalone system based DG set
}

\author{
Halima Ikaouassen ${ }^{1}$, Abderraouf Raddaoui ${ }^{2}$, Miloud Rezkallah ${ }^{3}$, Hussein Ibrahim ${ }^{4}$ \\ ${ }^{1,2}$ Mohammed V University in Rabat, MEAT, High School of Technology in Salé, B.P .227 Salé Medina, Morocco \\ ${ }^{3,4}$ Inergia, Cégep de sept-iles, sept-iles, Quebec, G4R 5B, Canada
}

\section{Article Info \\ Article history: \\ Received 26 Apr, 2019 \\ Revised Aug 11, 2019 \\ Accepted Nov 15, 2019}

\section{Keyword:}

Improved PCMC

Diesel generators

Adaptive PR controller

Saturation

\begin{abstract}
This paper investigates an improved current predictive model control (PCMC) strategy with a prediction horizon of one sampling time for voltage regulation in standalone system based on diesel engine driven fixed speed synchronous generator. An adaptive PR controller with anti-windup scheme is employed to achieve high performance regulation without saturation issues. In addition, new method to obtain the optimal parameters of the adaptive PR controller to achieve high performance during the transition and in steady state, is provided. Furthermore, to balance the power at the point of common coupling (PCC), as well as, to fulfilling a clean power to the connected loads, a three-phase voltage source inverter (VSI) with LRC filter is controlled using the developed improved PCMC strategy. The output filter current is controlled using the predicting of the system behaviour model in the future step, at each sampling prediction time. The performances of the developed control strategy are verified using Matlab/Simulink interface.
\end{abstract}

Copyright @ 2019 Institute of Advanced Engineering and Science. All rights reserved.

Corresponding Author:

Halima Ikaouassen,

MEAT, High School of Technology Salé B.P. 227 Salé medina,

Mohammed V university in Rabat, Morocco.

Email: halimaikaouassen@research.emi.ac.ma

\section{INTRODUCTION}

For many decades, the diesel generator (DG) has widely considered as a principal source of energy in many applications $[1,2]$ such as in nuclear power plants, industries, power generation units etc., due to their higher mechanical output power, fuel injection efficiency and high lifespan. Generally, the DGs are broadly opted in many remote and isolated villages in the absence of distribution grids [3, 4], due to the financial and technical constrains. In standalone power generation systems, the diesel engine (DE) is coupled with induction or synchronous machine to generate electricity; the mostly harnessed configuration is when the DE, is coupled with fixed speed synchronous generator and operates in parallel with renewableenergy sources (RESs) $[5,6]$ to supply all types of loads profiles and provides continuously power supply especially in remote areas installation.

Generally, in standalone power generation systems based on DG set which is connected to the AC/DC converters, the power quality issue represents the main challenge. Many solutions to mitigate harmonics using appropriate control algorithms are reported in the literature. In [7, 8], indirect control algorithms employed for voltage regulation in standalone systems. This control algorithm is a simple view of the point implementation but required more improvement especially during the transition due to use of the simple proportional integral controller (PI). The obtained results show good performances at the PCC in the presence of nonlinear loads. Furthermore. To overcome the issue related to the PI parameters tuning, 
an adaptive fuzzy logic based PID controller and adaptive neural network-based control algorithms have been investigated in [9-14]. However, saturation issue is solved, but the THD is not improved, especially when nonlinear loads, are connected. In [15, 16], Lyapunov function-based control approach has been investigated to improve the power quality and regulates the voltage at the PCC. In [15], an improved lyapunov function for a single stage inverter, is proposed for voltage regulation and power quality improvement at the PCC. In the proposed approach, one PI controller for DC-link voltage regulation is suggested. The obtained results show satisfactory perfroamnce, but the saturation issue is not considered in this study. Moreover, this algorithm is hard to implement requires more time compilation, which is not easy to implement in real time using simple microprocessors cheap.

Recently, predictive model-based control (PMC) has been suggested as robust control strategy by [17-19] to regulate the AC voltage constant and mitigate harmonics at the PCC. This concept based on prediction current and voltage control techniques for VSI connected to LRC filter is also suggested in [20-23]. Based on obtained results, the concept based on prediction is more suitable for applications as a standalone system, where the voltage regulation and harmonic mitigation at the PCC, are challenging. Many authors are adopted this concept, for example in [24], implementation of the current predictive control for shunt active power filter, is suggested. The obtained results show satisfactory performance. Unfortunalty, the system parameters to predict the behaviour of all systems in the next operating step is not taken on consideration in this study. Nevertheless, the algorithm should be reinforced by the simple and robust controller where the controller parameters and the saturation issue should be taken on consideration.

To overcome all issues already discussed, in this research work, an improved current predictive model control (PCMC) with one sampling time prediction for current control regulation at PCC using a threephase voltage source inverter (VSI) with LRC filter, is suggested the DG set based synchronous generators with fixed speed and diesel engine is used as a primary source to supply the connected three phases nonlinear, linear, balanced, unbalanced and dynamic loads; as it is presented in Figure.1.

The main contributions of this work are as follows:

a) Design and implementation of an outer control loop based Adaptive PR controller with anti-windup scheme instead of conventional PI controllers to overcome the saturation issues, to achieve optimal regulation for DC-link voltage, and to obtain the references of the output filter current, which are used as inputs for the phase locked loop.

b) Developing of improved PCMC based control strategy for current harmonics suppression and power quality improvement at the PCC. The improved PCMC used the standalone system based on DG set models to predict the behaviour of the balanced output filter current at each sampling time corresponding to the eight possible switching state of the three-phase VSI.

c) The proposed controller uses a cost function block to optimize the error between the output filter current and its reference generated by the proposed to improve PCMC strategy, in the future sampling time without PI controllers' requirements.

d) The improved PCMC confirms the IEEE 519 requirement standards against high-sampling prediction time value, under sudden changes of different types of nonlinear and dynamics load.

The organization of this paper is as follows: Section 2 gives in detail, the description of the standalone system based on DG set. Section 3 focuses on the modelling of the proposed standalone system-based DG set. Section 4 develops the proposed control algorithm. Finally, in the last section, the obtained simulation performances using Matlab/Simulink interface, have been discussed confirming and validate the proposed enhanced control approach, and conclusion is given to conclude the research work.

\section{DESCRIPTION OF STANDALONE CONFIGURATION SYSTEM}

Figure 1 presents standalone system configuration-based DG set for remote areas. The system under study consists of: DE driven fixed speed synchronous generator and Battery Energy Storage System (BESS). The DG set is connected directly to the PCC and the BESS is connected to the PCC through a three-phase voltage source inverter (VSI). The AC voltage at the terminals of synchronous generators are regulated at their rated values using (automatic voltage regulator) AVR and the system frequency are regulated by the governor. The voltage regulation at PCC is achieved by controlling the three-phase VSI using the improved current predictive model control (PCMC) strategy. An inductance-resistance-capacitor (LRC) filter is used to eliminate the ripple voltage created by the high-switching frequency of VSI. 


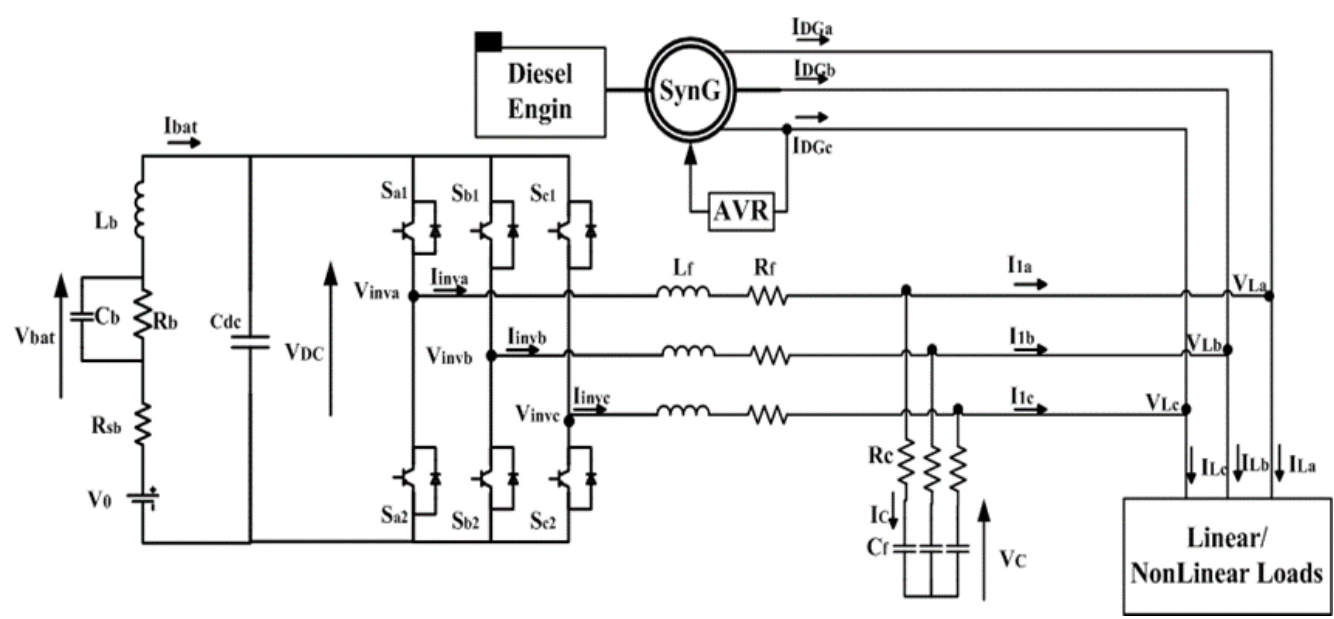

Figure 1. Standalone system configuration-based DG set

\section{MATHEMATICAL MODELS OF STANDALONE SYSTEM CONFIGURATION BASED DG} SET

\subsection{Mathematical model of diesel generator (DG) set}

The model presented in Figure 2 consists of four blocks: PID controller used to prevent the speed error at steady-state. Actuator and governor blocks to control the torque and therefore the mechanical power input to the generator, since the angular speed is fixated by the system frequency and cannot be changed by varying the power input, the governor settings determine the load level at which the machine operates. The engine block generates a mechanical torque after a time delay $\mathrm{e}^{-{ }^{\mathrm{ST}}}$, then it multiplied by the angular speed, one obtains the mechanical power of the diesel generator, which can be represented by the model [25]:

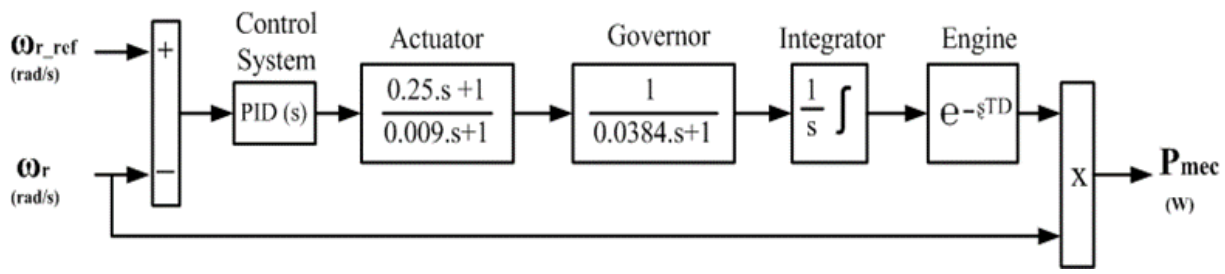

Figure 2. Mathematical model of diesel engine

\subsection{Mathematical model of the three-phase VSI}

The Figure 1 presents three-phase VSI with LRC filters and DC-link capacitors model in detail. Applied Kirchhoff laws to Figure 1, one obtained the linear mathematical model of each phase of the VSI with LRC filters are expressed by the following equations as:

$$
\left\{\begin{array}{l}
L_{f} \frac{d I_{\text {inva }}}{d t}=-R_{f} I_{i n v a}+V_{i n v a}-V_{C a} \\
L_{f} \frac{d I_{i n v b}}{d t}=-R_{f} I_{i n v b}+V_{i n v b}-V_{C b} \\
L_{f} \frac{d I_{i n v c}}{d t}=-R_{f} I_{i n v c}+V_{i n v c}-V_{C c}
\end{array}\right.
$$

The current through the filter capacitor is given as:

$$
\left\{\begin{array}{l}
I_{C a}=C_{f} \frac{d V_{C a}}{d t} I_{i n v a}-I_{1 a} \\
I_{C b}=C_{f} \frac{d V_{C b}}{d t}=I_{i n v b}-I_{1 b} \\
I_{C c}=C_{f} \frac{d V_{C c}}{d t}=I_{i n v c}-I_{1 c}
\end{array}\right.
$$


Equation (1) can be written as:

$$
\left\{\begin{aligned}
L_{f} \frac{d I_{1 a}}{d t} & =V_{i n v a}-V_{C a}-R_{f} I_{i n v a}-L_{f} \frac{d I_{c a}}{d t} \\
L_{f} \frac{d I_{1 b}}{d t} & =V_{i n v b}-V_{C b}-R_{f} I_{i n v b}-L_{f} \frac{d I_{c b}}{d t} \\
L_{f} \frac{d I_{1 c}}{d t} & =V_{i n v c}-V_{C c}-R_{f} I_{i n v c}-L_{f} \frac{d I_{c c}}{d t}
\end{aligned}\right.
$$

From previous (1-3), one obtains the following expression as:

$$
\begin{aligned}
& I_{i n v}=I_{1}+I_{C} \\
& I_{C}=C_{f} \frac{d V_{C}}{d t}
\end{aligned}
$$

where $I_{\text {inv }}$ and $V_{\text {inv }}$ denote the output three-phase VSI current and voltage respectively. $I_{1}$ represents the current at the output filter. $I_{C}$ is the current which passes through the filter capacitor and $V_{C}$ is the measured voltage across capacitors of the output ripple filter. Based on (3-5), one obtains the following expression that represents the variation of the capacitor voltage and the output LRC filter current as:

$$
\begin{aligned}
& \frac{d V_{C}}{d t}=\frac{1}{C_{f}}\left(I_{i n v}-I_{1}\right) \\
& \frac{d I_{1}}{d t}=-\frac{1}{L_{f}} V_{C}-\frac{R_{f}}{L_{f}} I_{1}-\frac{R_{f}}{L_{f}} I_{C}-\frac{d I_{C}}{d t}+\frac{1}{L_{f}} V_{i n v}
\end{aligned}
$$

The voltages $V_{\text {inva }}, V_{\text {invb }}, V_{\text {inc }}$ measured between the terminals $a, b, c$ and the DC-link of the three-phase VSI, can be expressed as:

$$
V_{\text {invk }}=S_{k} * V_{D C} \quad k=a, b, c \quad S_{k} \text { : leg switching variables }
$$

The phase voltage of the three-phase inverter is expressed as [26]:

$$
\left[\begin{array}{l}
V_{\text {inva }} \\
V_{\text {invb }} \\
V_{\text {invc }}
\end{array}\right]=V_{D C}\left[\begin{array}{lll}
1 & 0 & 0 \\
0 & 1 & 0 \\
0 & 0 & 1
\end{array}\right]\left[\begin{array}{l}
S_{a} \\
S_{b} \\
S_{c}
\end{array}\right]
$$

\section{IMPROVED PCMC STRATEGY FOR THREE-PHASE VSI}

The improved PCMC is based on the concept of predicting the attitude of the system at each switching state of the inverter. The aim of the suggested improved controller is to track the generated reference output filter current by choosing the suitable cost function defined as the error between the balanced output filter current and its reference, thus to achieve less THD without saturation issues at the PCC. Figure 3 describes the improved PCMC for the output filter current control. It consists of four blocks; 1) Reference current generation, 2) Extrapolation of the reference output filter current, 3) Prediction Current Model Control; and 4) Cost function optimization. The details of each block will be given in the following section in detail. As shown in Figure 3, the sensed filter current and the AC voltage is used to predict the output LRC filter current at the next sampling time $\mathrm{I}_{1}(\mathrm{k}+1)$.

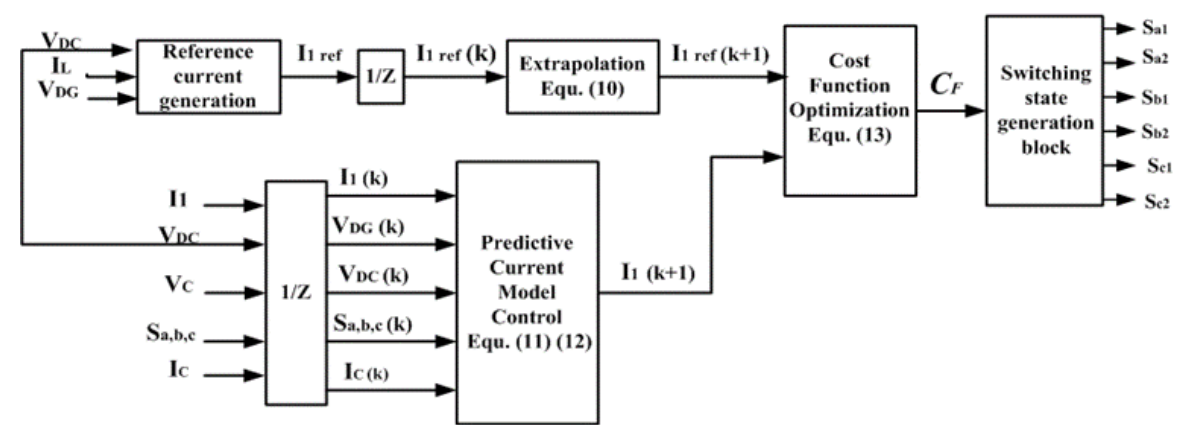

Figure 3. Improved PCMC strategy based adaptive PR controller for three-phase VSI 


\subsection{Reference current generation}

The generation of the reference filter current strategy is given in Figure 4. The proposed strategy used voltage and current control loops. In fact, the maximum current value at PCC is achieved by controlling the DC-link voltage using an adaptive PR controller with anti-windup scheme. A phase locked loop (PLL) block is used to generate sinusoidal signals, which are multiplied by the obtained maximum current terminal value; the terminal reference current is generated. Then by subtracting the terminal currents from the load current, the reference output filter current is generated.

\subsubsection{Design of the adaptive $P R$ controller with anti-windup scheme}

The transfer functions of the adaptive PR controller is considered as summation of the proportional part and the resonant part, and is expressed in the Laplace domain as [27]:

$$
P R(s)=K_{p}+R(s)
$$

where $K_{p}$ is the proportional part, and $R(s)=\frac{K_{r} \cdot S}{S^{2}+\omega_{r}^{2}}$ is the resonant part, and the $\omega_{r}$ is the resonant frequency, and $K_{r}$ is the resonant gain, respectively.

The discrete time of the adaptive PR controller is obtained using the mathematical form using Forward Euler's method as detailed in [27]: $s=\frac{T_{S}}{Z-1}$ where $T_{S}$ is the sampling prediction time. To make the controller adapted to the frequency variation, the resonant frequency is set equal to the DG set voltage using a PLL to ensure the operation stability during simulation scenarios: $\omega_{r}=2 \pi F_{r}$ where $F_{r}$ is the DG set voltage frequency given in the Table 1 . The system is prevented from going into deeper saturation by the use of anti-windup scheme described in the Figure 4. The difference defined between actual and saturated output $\mathrm{I}_{\mathrm{DGmax}}$ and $\mathrm{I}_{\mathrm{DGmax}}$ is ${ }_{\mathrm{S}}$ used as feedback response through a limited gain $\mathrm{K}_{\text {lim }}$. The aim is to reduce the error going into the resonant part of the adaptive PR controller as shown in Figure 4.

To protect both integrators used in the resonant part of saturation issues, the value of the limited gain $\mathrm{K}_{\text {lim }}$ should be set higher around the saturated output $\mathrm{I}_{\mathrm{DGmax} \text { SAT }}$, so the actual output $\mathrm{I}_{\mathrm{DGmax}}$ is kept unchanged which in turn enables the controller to come out of saturation. In addition, the value of the resonant gain $\mathrm{K}_{\mathrm{r}}$ is set higher and around the resonant frequency value, so that the controller forces the error to be zero at the steady state mode. The parameters design of the adaptive PR controller is achieved by adjusting gains, and for the anti-windup scheme, the parameters are set by adjusting the limit of the proportional and the resonant gains, using script in Matlab. The optimal parameters of the adaptive PR controller with anti-windup scheme are given in the Table 1.

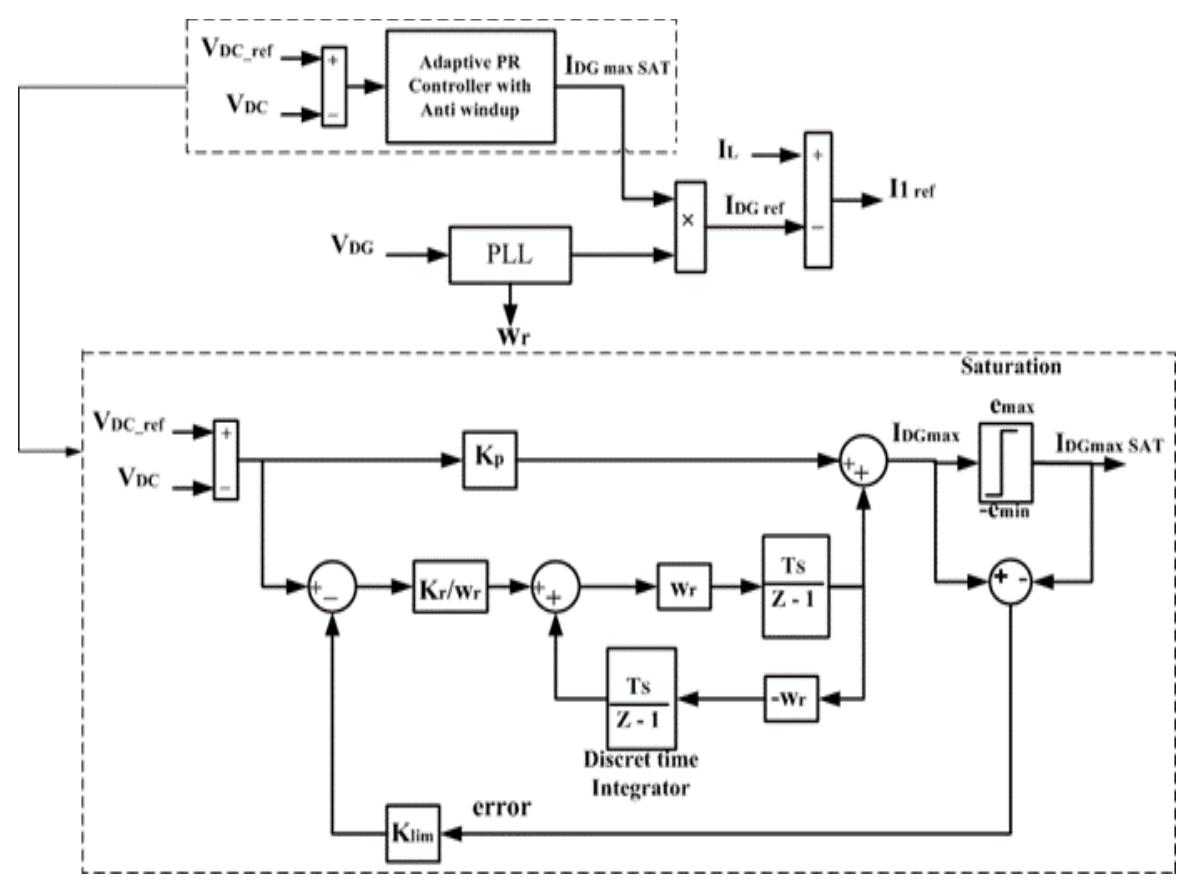

Figure 4. Reference output filter current generation block 
Table 1. The Parameters details of the Proposed System

\begin{tabular}{ll}
\hline Diesel Generator & $\mathrm{Pn}=2 \mathrm{~kW}, \mathrm{Vn}=400 \mathrm{~V}, \mathrm{Fr}=50 \mathrm{~Hz}, 2 \mathrm{p}=4$ \\
\hline AVR & $\mathrm{Kp}=10, \mathrm{Ki}=0.1, \mathrm{~K}_{\mathrm{D}}=1$ \\
PID & $\mathrm{Ka}=300, \mathrm{Ta}=0.001$ \\
Regulator & $\mathrm{Ke}=1, \mathrm{Te}=0$ \\
Exciter & $\mathrm{Kf}=0.001, \mathrm{Tf}=0.1$ \\
Dumping & $\mathrm{V}_{\mathrm{bat}}=375 \mathrm{~V}, \mathrm{~V}_{\text {batmax }}=441 . \mathrm{V}, \mathrm{R}_{\mathrm{b}}=10 \mathrm{k}$, \\
BESS & $\mathrm{C}_{\mathrm{b}}=12 \mu \mathrm{F}, \mathrm{L}_{\mathrm{b}}=200.10^{-6} \mathrm{H}, \mathrm{R}_{\mathrm{sb}}=0.32083 \Omega$ \\
& $\mathrm{K}_{\mathrm{p}}=0.8, \mathrm{~K}_{\mathrm{r}}=128, \boldsymbol{\omega}_{\mathrm{r}}=314 \mathrm{rad} / \mathrm{s}$, \\
Adaptive PR controller & $\mathrm{K}_{\mathrm{lim}}=10, \mathrm{e}_{\mathrm{max}}=10, \mathrm{e}_{\mathrm{min}}=-30$ \\
Anti-Windup scheme & $\mathrm{C}_{\mathrm{dc}}=2500 \mu \mathrm{F}$ \\
Three phase VSI & $\mathrm{L}_{\mathrm{f}}=10 \mathrm{mH}, \mathrm{R}_{\mathrm{f}}=6 \Omega, \mathrm{R}_{\mathrm{c}}=6 \Omega, \mathrm{C}_{\mathrm{f}}=10 \mu \mathrm{F}$ \\
LRC filter & $\mathrm{F}_{\mathrm{sw}}=10 \mathrm{kHz}$ \\
Switching frequency & $\mathrm{T}_{\mathrm{s}}=100 \mu \mathrm{s}$ \\
Sampling prediction time & \\
AC Loads & $\mathrm{R}_{\mathrm{L}}=16 \Omega$ \\
Linear load & $\mathrm{R}=12.5 \Omega, \mathrm{L}=20 \mathrm{mH}$ \\
RL Nonlinear load & $\mathrm{R}=9 \Omega, \mathrm{C}=1 \mu \mathrm{F}$ \\
RC Nonlinear Load &
\end{tabular}

\subsection{Extrapolation block}

The improved PCMC strategy requires extrapolation of the reference current $\mathrm{I}_{1 \text { ref }}$ to $\mathrm{k}+1$ sampling time in cost function computation. However, the sampling prediction $\mathrm{T}_{\mathrm{S}}$ should be higher than $20 \mu \mathrm{s}$. The reference of current is expressed as:

$$
I_{1 \text { ref }}(k+1)=I_{1 \text { ref }}(k)
$$

\subsection{Prediction model block}

The Euler approximation of the derivative current considered at the sampling time Ts is as:

$$
\left\{\begin{array}{l}
\frac{d I_{1}}{d t}=\frac{I_{1}(k+1)-I_{1}(k)}{T_{S}} \\
\frac{d I_{C}}{d t}=\frac{I_{C}(k+1)-I_{C}(k)}{T_{S}}
\end{array}\right.
$$

Both equations expressed in (11) are substituted in (12) to get the prediction expression of the output filter current at $(\mathrm{k}+1)$ for the eighth possible switching states of the three-phase VSI, where:

$$
\begin{aligned}
& I_{1}(k+1)=I_{1}(k)\left(1-\frac{R_{f} T_{S}}{L_{f}}\right)+\frac{T_{S}}{L_{f}}\left(V_{i n v}(k)-V_{C}(k)\right)+ \\
& {\left[I_{C}(k)\left(\frac{1}{T_{S}}-\frac{R_{f}}{L_{f}}\right)-\frac{1}{T_{S}} I_{C}(k+1)\right]}
\end{aligned}
$$

\subsection{Cost function optimization block:}

The control of output filter current is performed by choosing the appropriate cost function $\mathrm{C}_{\mathrm{F}}$ at every sampling prediction time, to minimize the error defined between the output filter current and its reference at the PCC, and it is expressed as:

$$
\begin{aligned}
& C_{F}=\left(I_{1 a r e f}(k+1)-I_{1 a}(k+1)\right)+\left(I_{1 b r e f}(k+1)-I_{1 b}(k+1)\right) \\
& +\left(I_{1 c r e f}(k+1)-I_{1 c}(k+1)\right.
\end{aligned}
$$

\section{SIMULATION DISCUSSIONS}

The performances of the developed improved control strategy for the three-phase VSI with LRC filters were tested and simulated in Matlab/Simulink interface. The parameters used for simulations are given in Table 1. The sampling prediction time $\mathrm{T}_{\mathrm{S}}$ is set at $100 \mu \mathrm{s}$, the rms $\mathrm{AC}$ voltage is set at $147 \mathrm{~V}$ and the load frequency is set equal to $50 \mathrm{~Hz}$. The proposed scenarios executed to validate the performance of the improved approach are as follows: a) sudden increase of linear load at $t=0.05 \mathrm{~s}$ and removed at $\mathrm{t}=0.2 \mathrm{~s} ; \mathrm{b}$ ) RL nonlinear load is connected from $t=0.3 \mathrm{~s}$ to $t=1 \mathrm{~s}, \mathrm{c}$ ) linear load is connected from $\mathrm{t}=0.4 \mathrm{~s}$ to $\mathrm{t}=0.6 \mathrm{~s} ; \mathrm{d}$ ) $\mathrm{RC}$ nonlinear load is connected from $\mathrm{t}=0.7 \mathrm{~s}$ to $\mathrm{t}=0.9 \mathrm{~s}$; and in e) load completely removed at $\mathrm{t}=1 \mathrm{~s}$. 
Figure 5 demonstrates the AC output filter current and its generated reference of one phase ' $a$ ' at next sampling time $\mathrm{k}+1$. One can clearly see that the $\mathrm{AC}$ output filter current $\mathrm{I}_{1}(\mathrm{k}+1)$ is well controlled and balanced with sinusoidal waveform; it tracks the generated reference $\mathrm{I}_{1 \text { ref }}(\mathrm{k}+1)$ with no saturation issue as it is obviously remarked in Figure 5(b) compared to the Figure 5(a) when using simple PI controller, and with less THD at PCC, which confirms the robustness of the improved PCMC approach. The PCMC algorithm is implemented for current harmonics suppression and power quality improvement at the PCC. To deal with sudden nonlinear and dynamics load changes and saturation issue, an improved PCMC algorithm is developed; it calculates the system parameters at each time when they changed according to the eight possible switching state of the three-phase VSI, to obtain a high quality of signal curves at the PCC under sudden changes of different kinds of nonlinear and dynamics loads. The Figure 6 presents the dynamic performance of the $\mathrm{DG}$ voltage $\left(\mathrm{V}_{\mathrm{DG}}\right)$ and current $\left(\mathrm{I}_{\mathrm{DG}}\right)$ of synchronous generator, load current $\left(\mathrm{I}_{\mathrm{L}}\right)$, output filter current $\left(I_{1}\right)$, inverter current $\left(I_{i n v}\right)$, DC-link voltage $\left(V_{D C}\right)$ and voltage field $\left(V_{f}\right)$ respectively. It is obviously remarked that the voltage of synchronous generator kept constant and regulated at the rated value, which is equal to equal to $208 \mathrm{~V}$.



(a)

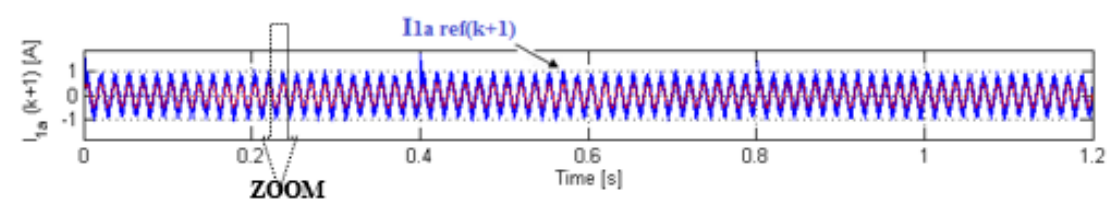

(b)

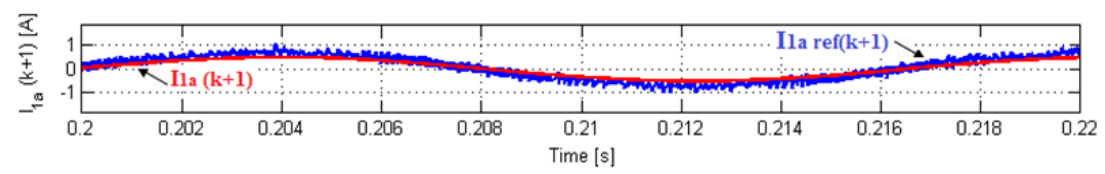

Figure 5. Waveforms of output filter current and its reference of one phase 'a', at PCC:

a) using simple PI controller b) using adaptive PR controller with Anti windup

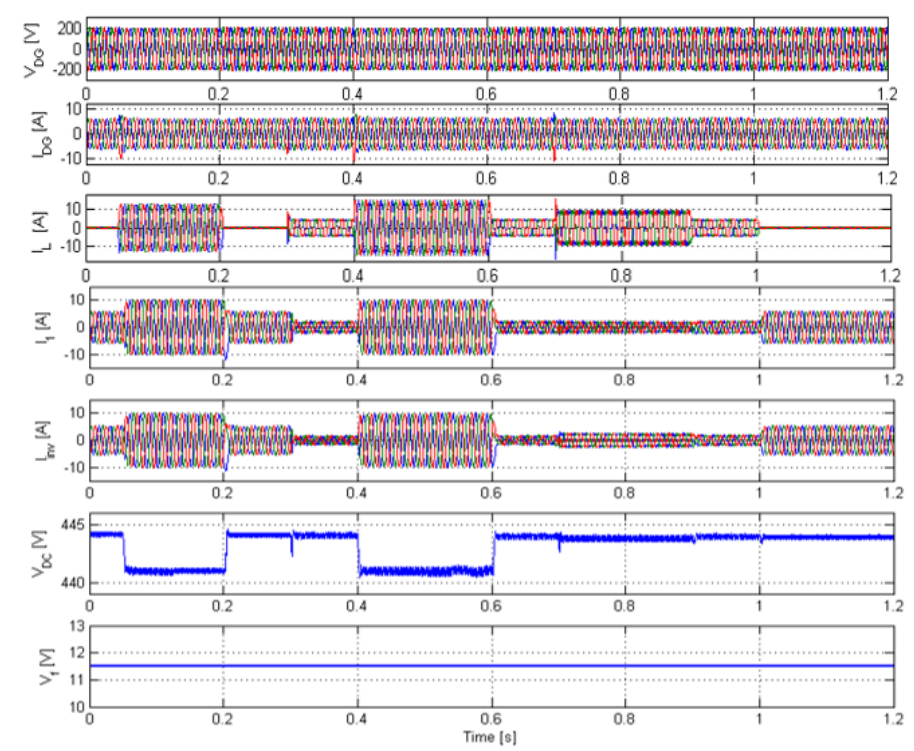

Figure 6. Simulation performances of $\mathrm{DG}$ voltage $\left(\mathrm{V}_{\mathrm{DG}}\right)$ and current $\left(\mathrm{I}_{\mathrm{DG}}\right)$, load current $\left(\mathrm{I}_{\mathrm{L}}\right)$, output filter current $\left(\mathrm{I}_{1}\right)$, inverter current $\left(\mathrm{I}_{\text {inv }}\right)$, DC-link voltage $\left(\mathrm{V}_{\mathrm{DC}}\right)$ and voltage field $\left(\mathrm{V}_{\mathrm{f}}\right)$ respectively during simulation scenarios 


\subsection{Dynamic currents performances at the PCC when the system is subjected to a sudden linear load} change

The behaviour of the system is firstly tested with no load, then the system is suddenly experienced to a linear load of $16 \Omega$, which is connected at $\mathrm{t}=0.05 \mathrm{~s}$, and removed at $\mathrm{t}=0.2 \mathrm{~s}$. The performances in detail are depicted in Figure 7. It is obviously remarked that the DG current is kept constant with sinusoidal waveform; during load change, harmonics are suppressed with diminished THD: $0.14 \%$. The load, output filter and inverter currents, are varied with sudden linear load changes. The saturation issue is obviously shown avoided with fewer ripples at a steady state mode and less THD for load current at the PCC: $0.098 \%$. This confirms the robustness of the improved PCMC based adaptive PR controller strategy during sudden linear load change.

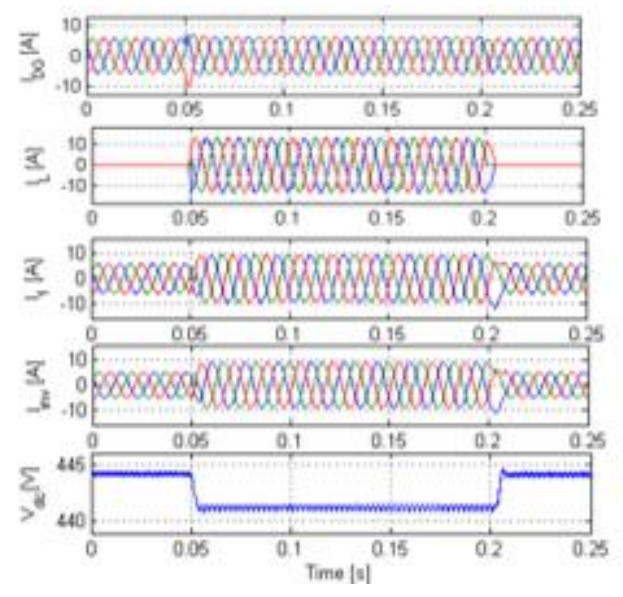

Figure 7. Simulation performances of dynamic AC currents and DC-link voltage under sudden linear load changes

\subsection{Dynamic currents performances at the PCC when the system is subjected to unbalance nonlinear and dynamic loads}

To prove the forcefulness of the improved PCMC based adaptive PR controller strategy and to apprise the performance of current harmonics suppression and power quality improvement at the PCC, RL dynamic nonlinear load is taken as three phase diode rectifiers with RLC shunt active filter. This load is applied during time between $t=0.3 \mathrm{~s}$ and $\mathrm{t}=1 \mathrm{~s}$. Firstly, an unbalanced linear load of $16 \Omega$, has been used and connected between $\mathrm{t}=0.4 \mathrm{~s}$ and $\mathrm{t}=0.6 \mathrm{~s}$. Then, between $\mathrm{t}=0.7 \mathrm{~s}$ and $\mathrm{t}=0.9 \mathrm{~s}$, an $\mathrm{RC}$ dynamic nonlinear load is taken as three phase diode rectifiers with shunt active filter; is applied to the system. The simulation responses are presented in detail in Figure 8(a) and 8(b) respectively. It is noticed that load, inverter and output filter current using improved PCMC present transient in their amplitudes due to unbalanced DG voltage at $\mathrm{t}=0.4 \mathrm{~s}$ and $\mathrm{t}=0.7 \mathrm{~s}$ with and less THD for load current at the PCC as, $1.2 \%$ and $0.24 \%$ respectively.
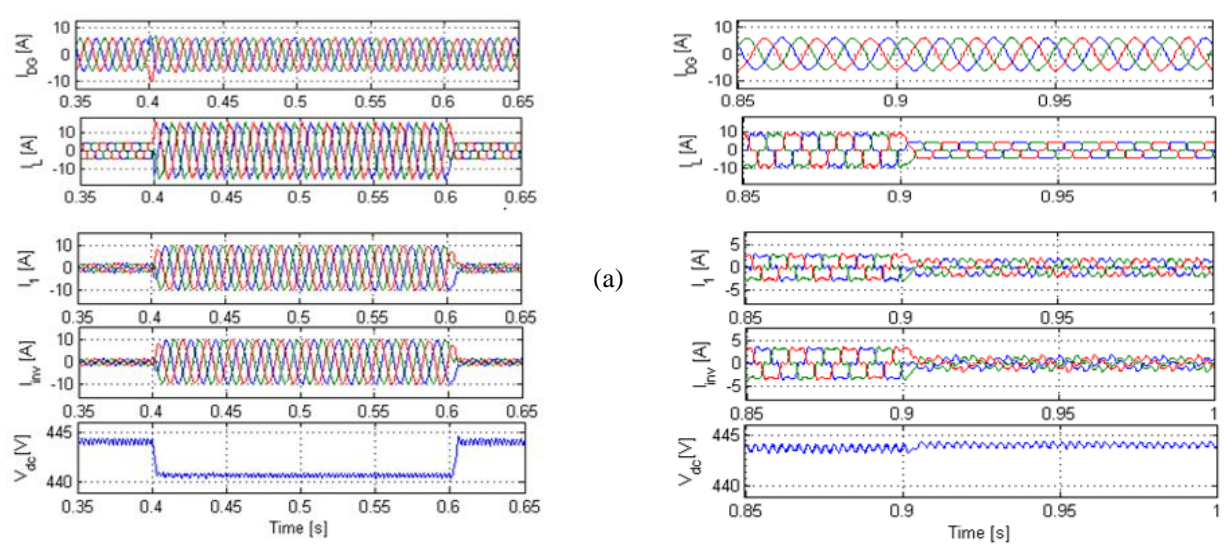

(b)

Figure 8. Simulation performances of dynamic AC currents and DC-link voltage under unbalanced nonlinear and dynamic loads 
It can be easily seen in the Figure 8, that the response of the DG current is balanced and sinusoidal and achieved with less THD as, $0.25 \%$ and $0.22 \%$ respectively, when unbalanced nonlinear and dynamic RC nonlinear loads, are connected. Furthermore, one observes that the DC-link voltage varies and the BESS charges and discharges during load change. For all scenarios, the saturation issues are avoided, which confirms the robustness of the developed control strategy based improved PCMC and adaptive PR controller with anti-windup scheme. Table 2 resumes the obtained THD values (\%) using Matlab/simulink interface, of the DG voltage, DG and load current at the PCC, in transient-state, with high-sampling time of prediction of $\mathrm{TS}=100 \mu \mathrm{s}$ under linear, $\mathrm{RL}$ and $\mathrm{RC}+\mathrm{RL}$ nonlinear load profiles.

Table 2. Simulation results of THD values of: DG voltage, DG and Load currents

\begin{tabular}{llccc}
\hline \multicolumn{1}{c}{ Load profiles } & & \multicolumn{3}{c}{ Sampling Prediction Time $\mathrm{T}_{\mathrm{S}}=100 \mu \mathrm{s}$} \\
& & $\mathrm{V}_{\mathrm{DG}}$ & $\mathrm{I}_{\mathrm{DG}}$ & $\mathrm{I}_{\mathrm{L}}$ \\
\hline Linear Load & THD $(\%)$ & 0.055 & 0.14 & 0.098 \\
RL Nonlinear Load & THD $(\%)$ & 0.12 & 0.25 & 1.2 \\
RC+RL Nonlinear Load & THD $(\%)$ & 0.095 & 0.22 & 0.24 \\
\hline
\end{tabular}

\section{CONCLUSION}

An improved PCMC algorithm has been investigated in detail for three phase VSI with LRC filters in standalone system based fixed speed DG sets. The proposed enhanced PCMC algorithm based on adaptive PR controller with anti-windup scheme is simulated in Matlab/Simulink interface. The Simulation results show satisfactory performance results under different conditions with less THD at the PCC, and without any saturation issue, which validates the proposed enhanced PCMC control strategy under high sampling prediction time against sudden nonlinear load profiles changes.

\section{REFERENCES}

[1] Niwas, R., et al, "Unity power factor operation and neutral current compensation of diesel generator set feeding three-phase four-wire loads," IET Generation, Transmission \& Distribution, 9(13): p. 1738-1746, 2015.

[2] Singh, B., et al, "Load leveling and voltage control of permanent magnet synchronous generator-based DG set for standalone supply system," IEEE Transactions on Industrial Informatics, 10(4): p. 2034-2043, 2014.

[3] Zubair, Ahmed, et al, "Optimal planning of standalone solar-wind-diesel hybrid energy systems for a coastal area of Bangladesh,” International Journal of Electrical and Computer Engineering, vol. 2, no 6, p. 731, 2012.

[4] NYO, Zin Mar, "Evaluation of PV, Wind, Diesel Hybrid Energy Potential for GSM Tower in Myanmar," International Journal of Electrical \& Computer Engineering, (2088-8708), vol. 5, no 6, 2015.

[5] Rezkallah, Miloud, et al, "Modified PQ control for power quality improvement of standalone hybrid wind diesel battery system," 2012 IEEE Fifth Power India Conference. IEEE, pp. 1-6, 2012.

[6] Rezkallah, Miloud, et al, "Real-time hardware testing, control and performance analysis of hybrid cost-effective wind-PV-diesel standalone power generation system," in 2017 IEEE Industry Applications Society Annual Meeting, IEEE, p. 1-8, 2017.

[7] Rezkallah, M. and A. Chandra, "Control of wind-diesel isolated system with power quality improvement," in Electrical Power \& Energy Conference (EPEC), IEEE, 2009.

[8] Bouderbala, Manale, et al, "Direct and indirect vector control of a doubly fed induction generator based in a wind energy conversion system," International Journal of Electrical and Computer Engineering, vol. 9, no 3, p. 1531, 2019.

[9] Hooshmand, R. and M. Moazzami, "Optimal design of adaptive under frequency load shedding using artificial neural networks in isolated power system," International Journal of Electrical Power \& Energy Systems, 42(1), p. 220-228, 2012.

[10] MADHAV, G. et al, "A New Hybrid Artificial Neural Network Based Control of Doubly Fed Induction Generator," International Journal of Electrical \& Computer Engineering (2088-8708), vol. 5, no 3, 2015.

[11] DABBAGHJAMANESH, M., et al, "High Performance Control of Grid Connected Cascaded H-Bridge Active Rectifier Based on Type II-Fuzzy Logic Controller with Low Frequency Modulation Technique,” International Journal of Electrical \& Computer Engineering (2088-8708), vol. 6, no 2, 2016.

[12] SANKAR, R. et al, "Adaptive Fuzzy PI Current Control of Grid Interact PV Inverter," International Journal of Electrical \& Computer Engineering (2088-8708), vol. 8, no 1, 2018.

[13] AMINE, Bouzid Mohamed, et al, "Adaptive fuzzy logic control of wind turbine emulator," International Journal of Power Electronics and Drive Systems, vol. 4, no 2, p. 241, 2014.

[14] SALIM, Sy, et al, "Robust Control Strategy for Pneumatic Drive System via Enhanced Nonlinear PID Controller," International Journal of Electrical \& Computer Engineering (2088-8708), vol. 4, no 5, 2014.

[15] Moutaki, K., et al, "Improved Lyapunov Function based Control Approach for Single-stage inverter Grid Interfacing Solar Photovoltaic System," In 2018 IEEE International Conference on Industrial Technology (ICIT), Lyon, pp. 1000-1005, 2018. 
[16] Moutaki, Kawtar, et al, "Lyapunov Function Based Control for Grid-Interfacing Solar Photovoltaic System with Constant Voltage MPPT Technique" In International Conference on Advanced Intelligent Systems for Sustainable Development. Springer, Cham, p. 210-219, 2018.

[17] IKAOUASSEN, Halima, et al, "Real-time implementation of improved predictive model control for standalone power generation system based PV renewable energy," IET Generation, Transmission \& Distribution, vol. 13, no 7, p. 1068-1077, 2019.

[18] SUNORI, Sandeep Kumar, et al, "Model Predictive Control System Design for Boiler Turbine Process," International Journal of Electrical and Computer Engineering, vol. 5, no 5, 2015.

[19] C. Schulte, et al, "Comparison of optimized pulse patterns with Direct Model Predictive Control using cosimulation," in 8th IET International Conference on Power Electronics, Machines and Drives, pp. 1-6, 2016.

[20] S. S. Lee, et al, "Finite control set model predictive control of nine-switch AC/DC/AC converter," in 2016 IEEE International Conference on Power and Energy, pp. 746-751, 2016.

[21] S. Bayhan, et al, "Finite-Control-Set Model-Predictive Control for a Quasi-Z-Source Four-Leg Inverter Under Unbalanced Load Condition," IEEE Transactions on Industrial Electronics, vol. 64, pp. 2560-2569, 2017.

[22] Scoltock, J., et al, "A model predictive direct current control strategy with predictive references for MV gridconnected converters with LCL-filters," IEEE Transactions on Power Electronics, 30(10): p. 5926-5937, 2015.

[23] Gulbudak, O. and M. Gokdag, "Improving supply current quality of dual-output four-leg Indirect Matrix Converter using model predictive control," in 2018 IEEE 12th International Conference on Compatibility, Power Electronics and Power Engineering (CPE-POWERENG 2018), Doha, pp. 1-6. 2018.

[24] Boukezata, Boualem, et al, "Implementation of predictive current control for Shunt Active Power Filter," in: 2017 6th International Conference on Systems and Control, IEEE, p. 133-138, 2017.

[25] Reddy, Y.J., et al, "PLC based energy management and control design for an alternative energy power system with improved power quality," International Journal of Engineering Research and Applications, 3(3), 2013.

[26] Chen, K., et al, "Two-level three-phase voltage source inverter fed low-power AC induction motor based on unipolar pulse-width modulation method," IET Power Electron., 9, pp. 435-440, 2016.

[27] El-Deeb, H., et al, "An adaptive PR controller for inverter-based distribution generation with active damped LCL filter," in 2013 7th IEEE GCC Conference and Exhibition (GCC), Doha, pp. 462-467. 2013.

\section{BIOGRAPHIES OF AUTHORS}

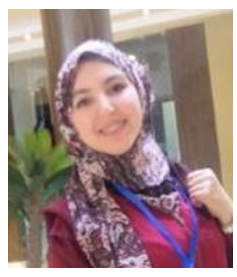

Halima Ikaouassen received the Electromechanical Engineering degree from Ecole Nationale Supérieure d'Arts et Métiers ENSAM-Meknès in 2013. She is a Ph.D student in Ecole Mohammadia d'Ingénieurs, Mohammad V University. She is a member of material, energy and acoustic team (MEAT). Her research interests include control and design of hybrid standalone, power quality, and renewable energy based photovoltaic generation systems/diesel generators reinforced by hybrid storage system.

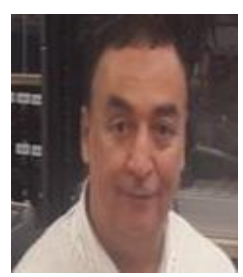

Abderraouf Raddaoui received the $\mathrm{PhD}$ degree in engineering from Perpignan University at Perpignan, France. And the M. Ing.degree in 'Renewable Energy and Energy Efficiency' from École de Technologie Supérieure, Université, Montréal, Canada. He is working as a Professor at École Supérieure de Technologie de Salé (ESTS), University Mohammed V in Rabat, Morocco. His research interests include Fuel cell, control and design of microgrid, power quality, renewable energy sources integration, hybrid energy power system, storage energy, heat and mass transfer, and energy efficiency.

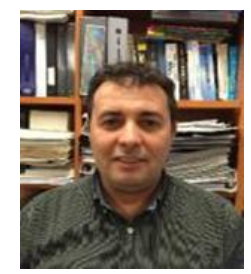

Miloud Rezkallah received the B. Tech. degree in electrical machines and drive from the University of Science and Technology USTO, Oran, Algeria, and the M. Tech. and Ph.D. degrees in power electronics and system control from École de Technologie Supérieure, Université, Montréal, Canada. in 2010 and 2016, respectively. He is working as researcher at research center on smart grids and energy systems (Inergia) at spet-iles in Quebec and as a research assistant in Electrical Engineering Department at École de Technologie Supérieure. His research interests include control and design of microgrid, power quality, renewable energy generations and applications, power management in smart grid, and energy storage systems.

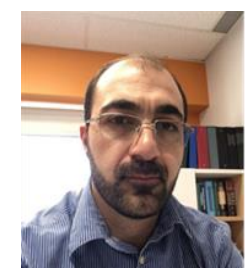

Hussein Ibrahim received the $\mathrm{PhD}$ degree in engineering from Québec University at Chicoutimi, Canada. Since July 2009, he has research director at Cégep of Spet-iles in the north of Quebec. His research interests include renewable energy sources integration, hybrid energy power system, storage energy, heat and mass transfer, fluid dynamics, and energy efficiency. 